\title{
Participants Mixed Strategy in Logistics Finance based on Game Theory
}

\author{
Qiao Jingyuan*, Wei Guili and Ke Jinchuan
}

\author{
School of Economics \& Management, Beijing Jiaotong University, Beijing 100044, P.R. China \\ Email: jyuanqiao1@163.com; jchke99@126.com
}

\section{Keywords: Logistics finance; Mixed strategy; Nash equilibrium; Inventory pledge loan}

\begin{abstract}
The function of logistics finance is the cooperation among lenders (banks), third-party intermediaries (logistics companies), and borrowers (SMEs, which means small to medium-sized enterprises). To develop logistics finance, this paper discusses the behavior of these three parties. The inventory pledge loan means the SME obtains loan from a bank with its inventories or other movables as collaterals, and the logistics company take the role to assess the collaterals and keep the collaterals with due care. With the cooperation of these three parties, logistics-company and SME would make the decision whether they will act in collusion to overestimate the value of collateral, the bank would decide whether it should supervise, their behaviors are discussed with Game Theory in the study. The result shows that there is no pure strategy Nash equilibrium, but there is a mixed strategy Nash equilibrium in this business. In other words the logistics-company and the SME will act in collusion with a specified probability, and the bank will also choose to supervise with another specified probability. Through Nash balance analysis of the mixed measures between bank and the interest groups composed by logistics-company and SME, an expectancy profits of the two are calculated, thus achieving the dynamic measures for self-gains of both parties.
\end{abstract}

\section{Introduction}

Most SMEs are facing the shortage of working capital, so they need borrowing money. However, with low credit ratings and lack of collateralized fixed assets, these SMEs have limited access to capitals, so it is a good choice for SMEs to apply for inventory pledge loans[2]. In this business, the SME obtains loans from the bank with its inventories or other movables as collaterals, meanwhile, the logistics company gets to assess and store the collaterals with due care. If the SME fails to repay the loans, the bank has the right to sell the mortgaged building property through auction.

Logistics-financial business makes it easier for SMEs to obtain bank loans through the participation of Logistics companies. However, the development of logistics-financial service is still at its initial stage due to the operating risk, asymmetric information risk, and collateral risk.

By analyzing these three risks, the operation risk is difficult to measure, as in the market-oriented economy, any economic activity is possible to come to loss. Loan default can be treated as probability event. As for the collateral risk, when selecting the collateral, the property with less damageability and good liquidity should be taken into account first. Therefore, among these three risks, the asymmetric information risk is the key to decide whether cooperation can be reached.

\section{Benefit analysis of participants in logistics finance}

Assumptions. SME obtains loans from a bank, with its inventories or other movables as collaterals, and the logistics company take the role to evaluate the collaterals and keep them with due care. When the loan is due, the SME is supposed to repay the loan with interests. If the SME fail to repay the loan, the bank has the right to sell the mortgaged building property through auction. The following parameters are set for the business[4]:

- Assuming the assessed value of the collaterals is $p_{1}$, the loan-to-value ratio is a, the value of loan is $p_{1} \times a$. When loan is due, the value of the collaterals is $p_{2}$. 
- The lending rate is $r_{1}$, which is the cost of capital for SME; The cost of capital for the bank is $r_{2}$. On the maturity date, the amount that the SME need to pay to the bank is $p_{1} \times a \times r_{1}$; the profit of the bank is $p_{1} \times a \times\left(r_{1}-r_{2}\right)$.To make sure that the SME is able to repay the loan, $p_{1} \times a \times r_{1}<p_{2}$ should be reached.

- The logistics enterprises are paid by the SME for evaluation and storage, and the fee is indicated by $F$.

- For the SME, the rate of return on the borrowed funds is $r_{3}$.

- If the SME acts in collusion with the logistics company, it will bribe the logistics company, assuming that the amount is $n$. Through the collusion, the logistics company can expand business, and its extra benefit is supposed to be $m_{b}$. They will overestimate the value of collateral as $p_{1}{ }^{\prime}$.

- Assuming the costs of supervision is $C_{1}$, but the supervision may not perform well sometimes. The probability that the supervision functions well is $w$ when the collusion exists.

- SME's loan default is a probability event, the probability for it to pay for the Principal and interest is $k_{1}$ without collusion, and $k_{2}$ is for the presence of collusion. $k_{1}>k_{2}$.

- If the Collusion between Logistics Company and SME is discovered, then the SME can not get a loan and they will have the reputation losses for $C_{2}$.

Benefits utility analysis. Now the benefits are represented by $R: R_{a}$ for the bank, $R_{b}$ for the logistics company, and $R_{c}$ for the SME. There are nine kinds of circumstances:

(1) Without information risk; the Logistics Company and the SME do not collude; the bank does not supervise, and finally, the SME repay loan.

$$
\begin{aligned}
& R_{a 1}=p_{1} \times a \times\left(r_{1}-r_{2}\right) \\
& R_{b 1}=F \\
& R_{c 1}=p_{1} \times a \times\left(r_{3}-r_{1}\right)-F
\end{aligned}
$$

(2) Without information risk; the Logistics Company and the SME do not collude; the bank does not supervise, but the SME can not afford the loan.

$$
\begin{aligned}
& R_{a 2}=p_{2}-p_{1} \times a \times\left(1+r_{2}\right) \\
& R_{b 2}=F \\
& R_{c 2}=p_{1} \times a \times\left(1+r_{3}\right)-F-p_{2}
\end{aligned}
$$

(3) With information risk; the Logistics Company and the SME collude; the bank does not supervise; and finally, the SME repay the loan.

$$
\begin{aligned}
& R_{a 3}=p_{1}{ }^{\prime} \times a \times\left(r_{1}-r_{2}\right) \\
& R_{b 3}=F+m_{b}+n \\
& R_{c 3}=p_{1}{ }^{\prime} \times a \times\left(r_{3}-r_{1}\right)-F-n
\end{aligned}
$$

(4) With information risk; the Logistics Company and the SME collude; the bank does not supervise; but the SME can not afford the loan.

$$
\begin{aligned}
& R_{a 4}=p_{2}-p_{1}{ }^{\prime} \times a \times\left(1+r_{2}\right) \\
& R_{b 4}=F+m_{b}+n \\
& R_{c 4}=p_{1}{ }^{\prime} \times a \times\left(1+r_{3}\right)-F-p_{2}-n
\end{aligned}
$$

(5) Without information risk; the Logistics Company and the SME do not collude; the bank supervises, and finally, the SME repay loan.

$$
\begin{aligned}
& R_{a 5}=p_{1} \times a \times\left(r_{1}-r_{2}\right)-C_{1} \\
& R_{b 5}=F
\end{aligned}
$$




$$
R_{c 5}=p_{1} \times a \times\left(r_{3}-r_{1}\right)-F
$$

(6) Without information risk; the Logistics Company and the SME do not collude; the bank supervises, but the SME can not afford the loan.

$$
\begin{aligned}
& R_{a 6}=p_{2}-p_{1} \times a \times\left(1+r_{2}\right)-C_{1} \\
& R_{b 6}=F \\
& R_{c 6}=p_{1} \times a \times\left(1+r_{3}\right)-F-p_{2}
\end{aligned}
$$

(7) With information risk; the Logistics Company and the SME collude; the bank supervises, and issues are exposed.

$$
\begin{aligned}
& R_{a 7}=-C_{1} \\
& R_{b 7}=n-C_{2} \\
& R_{c 7}=-n
\end{aligned}
$$

(8) With information risk; the Logistics Company and the SME collude; the bank supervises, but issues are not discovered. Finally, the SME repay loan.

$$
\begin{aligned}
& R_{a 8}=p_{1}{ }^{\prime} \times a \times\left(r_{1}-r_{2}\right)-C_{1} \\
& R_{b 8}=F+m_{b}+n \\
& R_{c 8}=p_{1}{ }^{\prime} \times a \times\left(r_{3}-r_{1}\right)-F-n
\end{aligned}
$$

(9) With information risk; the Logistics Company and the SME collude; the bank supervises, but issues are not discovered. The SME can not afford the loan at last.

$$
\begin{aligned}
& R_{a 9}=p_{2}-p_{1}{ }^{\prime} \times a \times\left(1+r_{2}\right)-C_{1} \\
& R_{b 8}=F+m_{b}+n \\
& R_{c 9}=p_{1}{ }^{\prime} \times a \times\left(1+r_{3}\right)-F-p_{2}-n
\end{aligned}
$$

To simplify these nine situations mentioned above, the following table lists their different behaviors and the corresponding benefits of the 3 stakeholders. $A, B$ and $C$ respectively represents the benefit of the bank, the logistics company and the SME. The choices of the Logistics Company and the SME are the same, so their interests should be analyzed as a whole[5].

Table 1 Benefits of the 3 stakeholders

\begin{tabular}{|l|c|c|}
\hline & Collude & Not Collude \\
\hline Supervise & $\left(A_{1}, B_{1}+C_{1}\right)$ & $\left(A_{2}, B_{2}+C_{2}\right)$ \\
\hline Not Supervise & $\left(A_{3}, B_{3}+C_{3}\right)$ & $\left(A_{4}, B_{4}+C_{4}\right)$ \\
\hline
\end{tabular}

The following can be deduced:

$$
\begin{aligned}
& A_{1}=w \times R_{a 7}+(1-w) \times\left[k_{2} \times R_{a 8}+\left(1-k_{2}\right) \times R_{a 9}\right] \\
& A_{1}=k_{1} \times R_{a 5}+\left(1-k_{1}\right) \times R_{a 6} \\
& A_{3}=k_{2} \times R_{a 3}+\left(1-k_{2}\right) \times R_{a 4} \\
& A_{4}=k_{1} \times R_{a 1}+\left(1-k_{1}\right) \times R_{a 2} \\
& B_{1}+C_{1}=w \times\left(R_{b 7}+R_{c 7}\right)+(1-w) \times\left[k_{2} \times\left(R_{b 8}+R_{c 8}\right)+\left(1-k_{2}\right) \times\left(R_{b 9}+R_{c 9}\right)\right] \\
& B_{2}+C_{2}=k_{1} \times\left(R_{b 5}+R_{c 5}\right)+\left(1-k_{1}\right) \times\left(R_{b 6}+R_{c 6}\right) \\
& B_{3}+C_{3}=k_{2} \times\left(R_{b 3}+R_{c 3}\right)+\left(1-k_{2}\right) \times\left(R_{b 4}+R_{c 4}\right) \\
& B_{4}+C_{4}=k_{1} \times\left(R_{b 1}+R_{c 1}\right)+\left(1-k_{1}\right) \times\left(R_{b 2}+R_{c 2}\right)
\end{aligned}
$$

As the above formula is too complicated to be compared an analysis from a realistic perspective should be conducted in order to obtain the maximum benefits [6]. If there is collusion between the logistics company and the SME, the banks will supervise to avoid greater losses. With the supervisions 
from the bank, the logistics company and the SME would not choose to cheat. If the logistics company and the SME do not collude, the bank would not supervise considering cost saving. But if the bank does not supervise, the collusion will occur, the logistics-company and the SME will act in collusion with a specified probability, and the bank will also choose to supervise with another specified probability [7].

\section{Analysis with Game Theory}

Let's make a simple assumption that payoff matrix for the issue discussed above is as follows:

Table 2 Assumption of Benefits of the stakeholders

\begin{tabular}{|l|c|c|}
\hline & Collude & Not Collude \\
\hline Supervise & $(1,-1)$ & $(-1,2)$ \\
\hline Not Supervise & $(-2,3)$ & $(2,2)$ \\
\hline
\end{tabular}

Both of the two parties intend to know the other's strategy, but they are not willing to get their own strategy be known. Therefore, they will choose the uncertain strategies to create uncertainty for each other [8]. Although it is not that clear as certain behaviors, it's reasonable to choose undefined behavior under such circumstances [9].

Suppose that the corporate parties infer that the bank supervise at the probability of $q$, and not to supervise at the probability of $1-q$.

For corporate parties, the benefit for collusion is $q \times(-1)+(1-q) \times 3=3-4 q$, the benefit for not collusion is $q \times 2+(1-q) \times 2=2$. If $q>1 / 4$, then $3-4 q<2$, the best choice for corporate parties is not to collude; If ,then $q<1 / 4,3-4 q>2$, the best choice for corporate parties is to collude; If $q=1 / 4$, two options are equivalent.

Assuming that the mix strategy of corporate parties is $(r, 1-r)$, which means the probability of collusion is $r$. According to previous analysis, when $q$ is given, the best strategy of the corporate parties is determined; the value of $\mathrm{r}$ can be calculated. For certain $q$ and $r$, the utility of the corporate parties is $r \times[q \times(-1)+(1-q) \times 3]+(1-r) \times[q \times 2+(1-q) \times 2]=2+r \times(1-4 q)$.

Suppose that the bank infer corporate parties collude at the probability of $r$, and not to collude at the probability of $1-r$. For the bank, the benefit for supervision is $r \times 1+(1-r) \times(-1)=2 r-1$; the benefit for not supervision is $r \times(-2)+(1-r) \times 2=2-4 r$. If $r>1 / 2$, then $2 r-1>2-4 r$, the best choice for the bank is to supervise; if $r<1 / 2$, then $2 r-1<2-4 r$, the best choice for the bank is not to supervise. If $r=1 / 2$, two options are equivalent. For certain $q$ and $r$, the utility of the bank is $q \times(2 r-1)+(1-q) \times(2-4 r)=2-4 r+q \times(6 r-3)$.

The $q^{*}(r)$ shows how $q$ influence $\mathrm{r}$. If $q>1 / 4$, then $r>0$; If $q<1 / 4$, then $r>1$; If $q=1 / 4$, $r$ can be any number between 0 and 1 . The $q *(r)$ shows how $\mathrm{r}$ influence $q$.
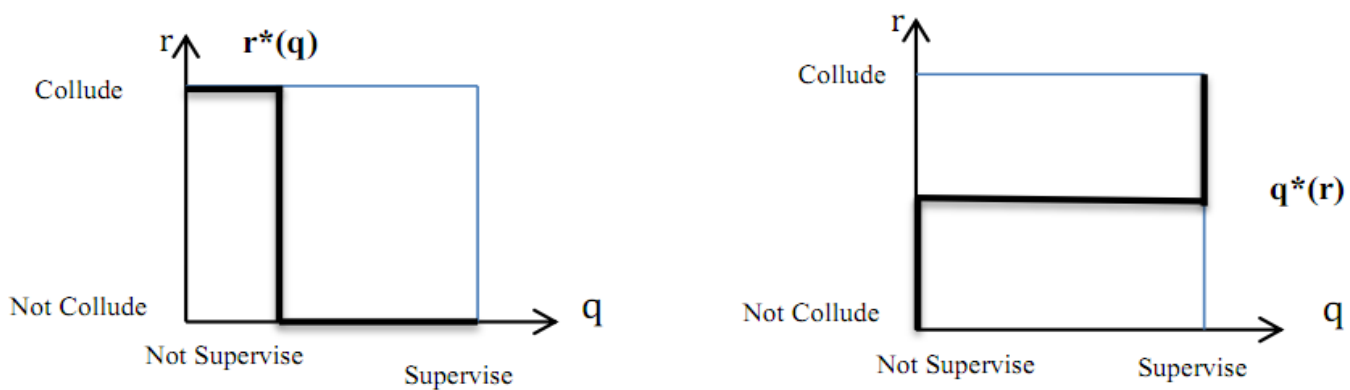

Fig. 1 The Relationship between $r$ and $q$ 
The Mixed strategy Nash equilibrium is $\{(1 / 4,3 / 4),(1 / 2,1 / 2)\}$, the bank choose to supervise at the probability of $1 / 4$, and not to supervise at the probability of 3/4. Two companies will collude at the probability of $1 / 2$, and not to collude at the probability of $1 / 2$.

The expected return is:

$$
\begin{aligned}
& \pi_{a}(q, r)=q r \times 1+q \times(1-r) \times(-1)+(1-q) r \times(-2)+(1-r)(1-q) \times 2=q \times(2 r-1)+(1-q)(2-4 r) \\
& \pi_{b+c}(r, q)=q r \times(-1)+q \times(1-r) \times 2+(1-q) r \times 3+(1-r)(1-q) \times 2=r(1-4 q)+2
\end{aligned}
$$

The expected return of bank is 0 , and the expect return of the corporate parties is 2 . With such outcome of the game, it is obvious that the bank is not willing do the business of logistics finance.

Taking Parameters into the Game Model. Suppose the bank decides to supervise at the probability of $q$, and logistics companies and SME collude at the probability of $r$.

For banks, the expected benefit of supervision is $r \times A_{1}+(1-r) \times A_{2}$; and for not supervision, the expected return is $r \times A_{3}+(1-r) \times A_{4}$. We need to calculate the value of $r$ to make sure the benefits of the bank supervision and no-supervision are equal. $r \times A_{1}+(1-r) \times A_{2}=r \times A_{3}+(1-r) \times A_{4}$. We solve it with Matlab:

$$
\begin{aligned}
& -C_{1}+r w\left(p^{\prime} a\left(1-k_{2} r_{1}+r_{2}-k_{2}\right)-\left(1-k_{2}\right) p_{2}\right)=0 \\
& r^{*}=\frac{C_{1}}{w} \frac{1}{p^{\prime} a\left(1-k_{2} r_{1}+r_{2}-k_{2}\right)-\left(1-k_{2}\right) p_{2}}
\end{aligned}
$$

If $r>r^{*}$, then $r \times A_{1}+(1-r) \times A_{2}>r \times A_{3}+(1-r) \times A_{4}$, the best choice for the bank is to supervise; If $r<r^{*}$, then $r \times A_{1}+(1-r) \times A_{2}<r \times A_{3}+(1-r) \times A_{4}$, the best choice for the bank is not to supervise. If $r=r^{*}$, then $r \times A_{1}+(1-r) \times A_{2}=r \times A_{3}+(1-r) \times A_{4}$, and two options are equivalent.

Suppose that the corporate parties composed by the logistics company and the SME infer bank supervision at the probability of $q$, at the probability of $1-q$ not to supervise. For corporate parties, the benefit for collusion is $q \times\left(B_{1}+C_{1}\right)+(1-q) \times\left(B_{3}+C_{3}\right)$. The benefit for not collusion is $q \times\left(B_{2}+C_{2}\right)+(1-q) \times\left(B_{4}+C_{4}\right)$.We need to calculate the value of q to make sure the benefit of the corporate parties' collusion and no-collusion are equal.

$$
q \times\left(B_{1}+C_{1}\right)+(1-q) \times\left(B_{3}+C_{3}\right)=q \times\left(B_{2}+C_{2}\right)+(1-q) \times\left(B_{4}+C_{4}\right)
$$

We can solve it as:

$$
\begin{gathered}
q w\left[\left(1-k_{2}\right) p_{2}-m_{b}-C_{2}\right]+q w p^{\prime} a\left[\left(1+r_{1}\right) k_{2}-r_{3}\right]=p^{\prime} a\left[\left(1+r_{1}\right) k_{2}-\left(1+r_{3}\right)\right]+p_{1} a\left[\left(1+r_{3}\right)-\left(1+r_{1}\right) k_{1}\right]+\left(k_{1}-k_{2}\right) p_{2}-m_{b} \\
q^{*}=\frac{1}{w} \frac{p^{\prime} a\left[\left(1+r_{1}\right) k_{2}-\left(1+r_{3}\right)\right]+p_{1} a\left[\left(1+r_{3}\right)-\left(1+r_{1}\right) k_{1}\right]+\left(k_{1}-k_{2}\right) p_{2}-m_{b}}{\left.\left(1-k_{2}\right) p_{2}-m_{b}-C_{2}\right]+q w p^{\prime} a\left[\left(1+r_{1}\right) k_{2}-r_{3}\right.}
\end{gathered}
$$

If $q>q^{*}$,then $q \times\left(B_{1}+C_{1}\right)+(1-q) \times\left(B_{3}+C_{3}\right)<q \times\left(B_{2}+C_{2}\right)+(1-q) \times\left(B_{4}+C_{4}\right)$, the best choice for corporate parties is not to collude;

If $q<q^{*}$, then $q \times\left(B_{1}+C_{1}\right)+(1-q) \times\left(B_{3}+C_{3}\right)>q \times\left(B_{2}+C_{2}\right)+(1-q) \times\left(B_{4}+C_{4}\right)$, the best choice for corporate parties is to collude;

If $q=q^{*}$, then $q \times\left(B_{1}+C_{1}\right)+(1-q) \times\left(B_{3}+C_{3}\right)=q \times\left(B_{2}+C_{2}\right)+(1-q) \times\left(B_{4}+C_{4}\right)$, Two options are equivalent.

Finally, the Mixed strategy Nash equilibrium is $\left\{\left(q^{*}, 1-q^{*}\right),\left(r^{*}, 1-r^{*}\right)\right\}$, the bank choose supervision at the probability of $q^{*}$, and no supervision at the probability of $1-q^{*}$. Two companies will collude at the probability of $r^{*}$, and not to collude at the probability of $1-r^{*}$.

Their expected return is:

$$
\pi_{a}(q, r)=q r \times A_{1}+q \times(1-r) \times A_{2}+(1-q) r \times A_{3}+(1-r)(1-q) \times A_{4}
$$




$$
\pi_{b+c}(r, q)=q r \times\left(B_{1}+C_{1}\right)+q \times(1-r) \times\left(B_{2}+C_{2}\right)+(1-q) r \times\left(B_{3}+C_{3}\right)+(1-r)(1-q) \times\left(B_{4}+C_{4}\right)
$$

Game Analysis. Asymmetric information risk is difficult to avoid. When logistics companies take their responsibilities to assess and custody the inventory, they may act in collusion to overestimate the value of collateral. Accordingly, the bank may supervise the behavior of them, and the cost of supervision should not be ignored. Through the previous analysis, the behavior of the bank, the logistics companies and the EMS will reach a mixed strategy Nash equilibrium: logistics-company and SEM act in collusion with a specified probability, and the bank choose to supervise with another specified probability. By using the above model, the value of these probabilities can be calculated by Eq.39 and Eq.41.

The Mixed strategy Nash equilibrium finally obtained is $\left\{\left(q^{*}, 1-q^{*}\right),\left(r^{*}, 1-r^{*}\right)\right\}$, which is, the bank conducts supervision at the probability of $q^{*}$, and conducts no supervision at the probability of $1-q^{*}$. Two companies will collude at the probability of $r^{*}$, and not to collude at the probability of $1-r^{*}$.

When the Mixed strategy is determined, the expected return of the participants can be assured by Eq.42 and Eq.43. Thus, when selecting the pricing model, the bank tries to make $\pi_{a}(q, r)$ as large as possible, and logistics companies and finance companies try to make $\pi_{b+c}(r, q)$ greater. Only when the parties are able to obtain the desired benefits will the logistics finance has a great development.

\section{Conclusion}

In the pricing process of logistics finance services, it is difficult to find out the most critical factor to maximize the returns of each party. In the situation when other parameters are given, if we want to change the value of a certain parameter, such as the lending rates, the loan-to-value ratio or others, we might as well measure the change of their benefits at the mixed strategy Nash equilibrium. It can be used to evaluate the reasonableness of the pricing of logistics finance.

\section{Acknowledgements}

This paper is partially supported by the Student Innovation Training Project of Beijing Jiaotong University.

\section{References}

[1] S.L. Tang and T.T. Qiao, Development of logistics finance to strengthen the integration of supply chain,Logistics Technology, 2(2006)99-102.

[2] B. Chen, Game research on the logistics financial system of profit distribution, J. of Putian University, 20 (2013) 26-29.

[3] J. Li, The new field of logistics services, China Logistics \& Purchasing, 11(2015) 70-72.

[4] J.C. Dong and D.F. Zhang, Game analysis of logistics financial business risk, Modern Management Science, 10(2011) 28-31.

[5] G.P. Yuan, Logistics finance participation with optimal decision analysis, Research on Financial and Economic Issues, 9(2011) 100-107.

[6] R.H. Sun and Z. Yang, Logistics finance service contract based on inventory pledge loan, Friends of Accounting, 2(2015)84-88.

[7] Z. B. Chen, Optimization of inventory pledge loan logistics financial services, Logistics Technology, 30 (2011) 95-98. 
[8] G.M. Wu, Principles and Application of Game Theory, Southeast University Press, 2009.

[9] C. Wang, Logistics financial cooperation and income distribution strategy, Logistics Engineering and Management, 33 (2011) 75-78.

[10] Information on http://en.wikipedia.org/wiki/Coordination_game. 